\title{
O ENSINO DE GEOGRAFIA E HISTÓRIA EM UMA PERSPECTIVA INTERCULTURAL
}

\author{
Julia Lobato Pinto de Moura ${ }^{1}$
}

Fábio de Farias Soares ${ }^{2}$

\section{RESUMO}

Este artigo objetiva apresentar uma proposta de ensino de Geografia e História em uma perspectiva intercultural, que promova um diálogo entre diferentes tipos de saberes, reconhecendo que há limites e fronteiras entre as mitologias e as ciências. É resultado de uma pesquisa bibliográfica e documental. Partindo das propostas teóricometodológicas de Claval (2006), Hall (2003), Santos (2007) e outros, busca-se analisar a importância de questionar a hegemonia do pensamento científico na construção de um ensino de ciências humanas menos etnocêntrico. A pesquisa documental traz um breve recorte da trajetória do debate sobre pluralidade cultural nos currículos da Educação Básica. Procura-se refletir como é possível dar diferentes significados e versões aos acontecimentos, e como isto é produzido historicamente, não havendo uma única verdade. As narrativas de tradição oral podem dialogar com as ciências em aulas de Geografia e História atentas aos etnoconhecimentos e a diversidade epistêmica dos saberes históricos e socioespaciais.

\section{PALAVRAS-CHAVE}

Geografia. História. Mitologia. Currículo. Pluralidade Cultural.

\section{THE TEACHING OF GEOGRAPHY AND HISTORY FROM AN INTERCULTURAL PERSPECTIVE}

\section{ABSTRACT}

This paper aims to present a proposal for the teaching of Geography and History from an intercultural perspective, which promotes a dialogue between different types of knowledge, recognizing the limits and borders that exist between mythologies and sciences. It is the result of bibliographical and documentary research, that takes the theoretical-methodological proposals formulated by Claval (2006), Hall (2003), Santos (2007) and others as a starting point, and seeks to analyze the importance of questioning the hegemony of scientific thought in the construction of a less ethnocentric model of teaching humanities. The research offers a brief literature review on the debate about cultural plurality in the curricula of Basic Education, and seeks to reflect on the possibility to give different meanings and versions to events, and on how these are historically produced, as opposed to being repositories of single truths. The narratives of oral tradition can dialogue with the sciences in classes of Geography and History attentive to the ethnocognitions and the epistemic diversity of historical and socio-spatial knowledge.

\section{KEYWORDS}

Geography. History. Mythology. Curriculum. Cultural Plurality.

1 Mestre em Letras: Linguagem e Identidade pela Universidade Federal do Acre (2016) e professora efetiva dessa mesma Instituição Federal de Ensino, com atuação no Curso de Geografia. 2 Graduado em História pela Universidade Federal do Acre (2017) 


\section{Introdução}

O presente trabalho é parte das reflexões desenvolvidas no Projeto de Extensão "Etnogeografia e História dos antigos: contadores nas escolas" que buscou promover um diálogo entre o conhecimento científico e algumas mitologias para pensar o ensino de Geografia e História em uma perspectiva menos etnocêntrica. Existem diferentes possibilidades de explicação para os fenômenos do mundo, de modo que interessounos explorar o universo da contação de histórias para pensar a geograficidade e historicidade do pensamento mítico, e como este pode enriquecer o currículo de História e Geografia na Educação Básica.

A complexidade do pensamento humano tem nos levado a atribuir diferentes significados às diversas manifestações da natureza. Cada povo, em diferentes lugares do planeta, foi desenvolvendo um significado especial para as experiências com o seu meio e os fenômenos que o cerca. Destas formas de se perceber o mundo, se concretizam os conhecimentos específicos que, paulatinamente, dão vida a uma cultura.

Propomos um planejamento na área de Geografia e História utilizando como recurso didático algumas narrativas de tradição oral e escrita sobre a origem do mundo e da humanidade, no intuito de construir uma proposta de ensino intercultural que promova um diálogo de saberes e explore as diferenças e semelhanças entre as teorias científicas e as mitologias. A proposta é elaborar um plano de aula sobre a origem do mundo e da humanidade que proponha um diálogo entre as concepções científicas e não-científicas sobre o tema, diferencie teoria de mitologia, e socialize conhecimentos de mitologias historicamente silenciadas, como as dos africanos e afrodescendentes no Brasil.

Não existe uma única versão sobre os fatos históricos de modo que é possível narrá-los de diferentes formas, em diferentes linguagens, e sob distintos pontos de vista. A validação destes conhecimentos, porém, depende dos valores culturais historicamente produzidos e tornados hegemônicos. A questão é: Não seriam as narrativas de 
diferentes povos sobre suas explicações de mundo, organização espacial, hábitos alimentares, costumes em geral, formas de se produzir um conhecimento histórico e geográfico para aquele povo?

Para produção deste trabalho realizamos uma revisão bibliográfica sobre o tema tendo como referência as propostas teórico-metodológicas de Paul Claval (2006), que embasa nossas reflexões sobre etnogeografias, de Stuart Hall (2003) que apresenta uma abordagem da questão cultural pela ótica marxista criticamente aplicada, e faz um convite para se pensar questões culturais para além de simplórios pluralismos e multiculturalismos, e de Michel Foucault (1996), que nos ajuda a pensar a relação entre a prática discursiva e os fatos históricos, o papel dos sujeitos e das instituições que detêm a autoridade para produzir as narrativas sobre os fatos como verdades universais.

Dão suporte os estudos de Mircea Eliade (1972) sobre as características dos mitos, de Adornoe Horkheimer (1985) sobre os limites e as fronteiras entre mito e ciência e de de Souza (2007) sobre a "ecologia dos saberes" e a crítica a "monocultura da ciência moderna". Apresentamos também uma breve análise documental da trajetória do debate sobre pluralidade cultural no ensino desde os Parâmetros Curriculares Nacionais (PCN, 1998) até a terceira versão da atual Base Nacional Curricular Comum (BNCC, 2017), passando pelas leis $n^{\circ} 10639 / 2003$ e $11.645 / 2008$ e pelas Diretrizes Curriculares Nacionais Gerais da Educação Básica (DCN, 2013).

0 universo

político

influência profundamente as práticas educacionais e neste sentido, analisamos também alguns movimentos contrários aos debates sobre pluralidade cultural e identidade de gênero nas escolas, como o Projeto de Lei (PL) intitulado "Escola Sem Partido". Projetos como este é um retrocesso em relação aos avanços recém-conquistados, pois abre precedente para que conteúdos como história e cultura afrobrasileira e indígena, identidade de gênero e combate a homofobia, entre outros, passem a ser considerados um atentado contra 
as "convicções morais" de alguns alunos ou de seus pais.

A importância da abordagem intercultural na educação legislação, pluralidade cultural e currículo de Geografia e História

A educação é indissociável das práticas políticas como toda ação humana: encontra-se amparada por um sistema legal, envolve relação de poder-saber hierarquizadas e é amplamente difundida como prática social. Portanto ela reflete as concepções daquelas sociedades que a produzem e seus objetivos. Para padronizar as diretrizes sobre o que e como ensinar existe os diferentes currículos. Cada pessoa que entra em contato com o sistema educacional e os conhecimentos nele difundidos o faz mediado pela relação com os professores, que são em grande parte definidas pelo currículo, por sua vez definido por uma autarquia de gestores.

Para a concretização de uma abordagem menos etnocêntrica dentro do currículo, é importante perceber-se amparado por alguns dispositivos legais que auxiliam nesse sentido. Reconhecemos que houve avanços na legislação desde a nova Lei de Diretrizes e Bases da Educação Nacional (1996) no sentido de nortear uma prática educativa para a questão da pluralidade cultural. Estes avanços na legislação, porém, não garantem que a prática educativa no cotidiano tão diverso das realidades brasileiras esteja realmente promovendo um diálogo e valorização de culturas historicamente silenciadas, e que é base da formação da sociedade brasileira, como as culturas indígenas e afro-brasileiras. Muitas conquistas merecem ser comemoradas a partir das ações desencadeadas com a promulgação das leis $n^{\circ} 10639 / 03$ e $n^{\circ} 11645 / 08$, que instituíram a obrigatoriedade do ensino de história e cultura afro-brasileira e indígena nas escolas, mas não tem sido um movimento isento de conflitos, e o Projeto "Escola Sem Partido" parece-nos apontar na contramão destes avanços.

Como descreve o documento das Diretrizes Curriculares Nacionais Gerais da Educação Básica (DCN, 2013) o histórico da construção de abordagens multiculturais nasceu de movimentos internacionais e nacionais de resistência de grupos 
considerados como minoritários e que eram excluídos da sociedade. A força adquirida ao longo dos anos, em especial nas últimas décadas, pressionou o governo a adotar medidas no sentido de políticas que reparassem estas desigualdades históricas. Dessa maneira, aparatos legais foram paulatinamente incorporados ao regime jurídico brasileiro, sobretudo no que tange os direitos das populações tradicionais, indígenas, pretas, quilombolas, homoafetivas, com deficiência, etc.

As mudanças começam a partir da Constituição de 1988, que garantiu no art. 205 ser a Educação um "direito de todos e dever do Estado e da família" e visa "ao pleno desenvolvimento da pessoa, seu preparo para o exercício da cidadania e sua qualificação para o trabalho" (BRASIL, 1988). A partir de então iniciaram os debates sobre a reformulação da LDB em vigor desde 1971, e a nova Lei de Diretrizes e Bases da Educação Nacional (LDB) (Lei nº 9394/96) prevê no art. 26 que haverá um núcleo comum para o currículo do ensino fundamental e médio e uma parte diversificada em função das peculiaridades locais.
A partir de então, educadores de diversas áreas passaram se reunir até que no final da década de 1990 foram lançados os PCN de todas as disciplinas do ensino fundamental e médio, para construir uma referência padronizada a nível nacional, além dos PCN de temas transversais. Esses documentos já contemplavam a questão da necessidade de uma escola aberta ao debate sobre orientação sexual, pluralidade cultural e respeito mútuos, pois "Para viver democraticamente em uma sociedade plural é preciso respeitar e valorizar a diversidade étnica e cultural que a constitui" (BRASIL, 1998, p. 68).

Nos chamados "Temas Transversais", o PCN nos revela o quão são variadas as possibilidades de desenvolvimento dessas temáticas, e salienta que a escola como parte da sociedade, está indissociável de seu caráter político, pois:

o compromisso com a construção da cidadania pede necessariamente uma prática educacional voltada para a compreensão da realidade social e dos direitos e responsabilidades em relação à vida pessoal e coletiva e a 
afirmação do princípio da participação política (BRASIL, 1998, p. 17).

As práticas de ensino atentas à pluralidade cultural nos possibilitam fortalecer o combate em uma luta antiga travada no Brasil contra a discriminação dos povos historicamente vitimados e escravizados durante séculos. Neste sentido o PCN de Temas Transversais aponta como um dos objetivos do ensino fundamental, por exemplo,

conhecer a diversidade do patrimônio etnocultural brasileiro, cultivando atitude de respeito para com pessoas e grupos que a compõem, reconhecendo a diversidade cultural como um direito dos povos e dosindivíduos e elemento de fortalecimento da democracia; (...) desenvolver uma atitude de empatia e solidariedade para com aqueles que sofrem discriminação"; repudiar toda discriminação baseada em diferenças de raça/ etnia, classe social, crença religiosa, sexo e outras características individuais ou sociais; exigir respeito para si e para o outro, denunciando qualquer atitude de discriminação que sofra, ou qualquer violação dos direitos de criança e cidadão (BRASIL, 1998, p. 143).

A LDB sofreu uma significativa alteração com as leis $n^{\circ} 10.639 / 03$ e $n^{\circ} 11.645 / 08$ que incluem no currículo oficial da rede de ensino a obrigatoriedade da temática "História e Cultura Afro-Brasileira e Indígena", e como descrito no art. 26-A, parágrafo $1^{\circ}$, prevê como conteúdo programático "a cultura negra e indígena brasileira e o negro e o índio na formação da sociedade nacional, resgatando as suas contribuições nas áreas social, econômica e política" (BRASIL, 2008) entre outros. Neste sentido nota-se que ocorreram alguns avanços em direção a uma maior justiça social e promoção de um currículo que valoriza as populações historicamente violentadas por séculos, e que ainda hoje sofrem diversos tipos de desrespeito aos direitos adquiridos e discriminação em geral. Porém visões estereotipadas sobre estes grupos étnicos foram difundidas durante séculos, de modo que o desconhecimento e o forte preconceito ainda arraigado na sociedade brasileira dificultam a aplicação das referidas leis, como apontam as pesquisas de Santana (2010), Gatinho (2012), Cruz e Jesus (2013).

As novas DCN surgem em 2013 como um novo referencial, no intuito de atualizar os PCN, o 
que levou ao aprofundamento nas questões de interesse e caráter regional, como a questão da educação quilombola. As novas DCN enfatizam que a defesa de uma educação multicultural emerge do contexto e necessidade de "compreender como as identidades e as diferenças são construídas e que mecanismos e instituições estão implicados na construção das identidades, determinando a valorização de uns e o desprestígio de outros" (BRASIL/DCN, 2013, p. 107).

Dessa forma, alguns grupos antes considerados minoritários e fortemente discriminados passam a integrar as discussões escolares. A concepção de currículo do DCN explica que os componentes curriculares não se esgotam ou se resumem às áreas de conhecimento, pois valores, atitudes, sensibilidades e orientações de conduta são veiculados na busca de promoção de uma sociedade mais justa e

A leitura e a escrita, a História, as Ciências, a Arte, propiciam aos alunos o encontro com um mundo que é diferente, mais amplo e diverso que o seu. Ao não se restringir à transmissão de conhecimentos apresentados como verdades acabadas e levar os alunos a perceberem que essas formas de entender e de expressar a realidade possibilitam outras interpretações, a escola também oferece lugar para que os próprios educandos reinventem o conhecimento e criem e recriem cultura (BRASIL/DCN, 2013, p. 116).

A perspectiva multicultural no currículo é apresentada no DCN, o que contribui para ampliação dos debates iniciados com os PCN, e favorece o reconhecimento e valorização das produções culturais de indivíduos e grupos sociais marginalizados, contribuindo para o combate a discriminação manifesta no interior da escola e na sociedade em geral. Porém, como aponta Hall (2003), apesar da ênfase dada à temática nas últimas décadas, com um maior reconhecimento das diferenças, busca pela igualdade e justiça, há ainda muitas dificuldades na expansão da prática política na lógica multicultural.

No ensaio sobre $A$ questão multicultural Hall sugere que o termo multiculturalismo é hoje utilizado universalmente para se referir as estratégias e políticas adotadas para administrar/ governar os "problemas" de 
diversidade em sociedades multiculturais. Ele apresenta três tipos de abordagens do multiculturalismo: o conservador, o pluralista e o crítico, apontando que o conceito é diverso, contraditório e oscilante.

Santos

(2003) também defende que é fundamental que se distingua entre as formas colonialistas, conservadoras ou reacionárias das formas críticas, progressista e inovadoras de multiculturalismo. É neste contexto de crítica ao multiculturalismo que surge a proposta intercultural. Soriano apud Damázio (2008) destaca que muitos autores empregam o mesmo significado para denominar o multiculturalismo e o interculturalismo, porém defende ser mais adequado

$\begin{array}{lr}\text { utilizar o } & \text { termo } \\ \text { multiculturalismo } & \text { para } \\ \text { a constatação } & \text { empírica } \\ \text { da coexistência } & \text { das } \\ \text { culturas, enquanto que o } & \text { qua } \\ \text { interculturalismo tem uma } \\ \text { pretensão normativa ou } \\ \text { prescritiva e diz respeito à } \\ \text { exigência de um tratamento } \\ \text { igualitário dispensável às } \\ \text { culturas (Soriano, 2004, p. } \\ \text { 91apud Damázio 2008, p. 76). } \\ \text { opção feita neste artigo }\end{array}$

de usar o termo intercultural e suas variáveis ao invés de multicultural é uma opção a partir deste debate, que sugere que diferente dos termos multi e pluricultural, o inter remete não só a constatação da diversidade, mas, principalmente, a uma coexistência das culturas em um plano de igualdade. "A interculturalidade alude a um tipo de sociedade em que as comunidades étnicas, os grupos sociais se reconhecem em suas diferenças e buscam uma mútua compreensão e valorização" (DAMÁZIO, 2008, p. 77).

As concepções de Hall, de Santos, e outros, são de grande valia quando situamos que, apesar de um discurso voltado para afirmação das diferenças, o multiculturalismo muitas vezes torna-se vazio, seja por não situar historicamente suas origens, ou no outro extremo, por dá-las como resolvidas, consequência natural do período pós-colonial. Há ainda, as forças contrárias a este movimento, que começam a se organizar.

Um dos resultados desta organização de forças político- 
ideológicas contrárias ao debate sobre a diversidade e o respeito às diferenças nas escolas é a notória retirada do termo "orientação sexual" da BNCC (2017). Em 1998, quando foi lançado o PCN de Orientação Sexual o termo "identidade de gênero" e o debate sobre a violência associada a homofobia ainda não era difundido como é hoje, mas o documento já apontava para a necessidade da escola contribuir para o conhecimento e valorização dos direitos sexuais e reprodutivos, para que homens e mulheres tomem decisões sobre sua fertilidade, saúde reprodutiva, criação de filhos, prevenção de doenças sexualmente transmissíveis e problemas graves, como o abuso sexual, a gravidez indesejada, desigualdade de gênero.

0 documento de 52 páginas salienta que "as palavras, comportamentos e ações dos pais configuram o primeiro e mais importante modelo da educação sexual das crianças" (1998, p. 291), mas não são os únicos agentes sociais e estímulos que farão parte do processo. A mídia também contribui, seja divulgando imagens eróticas, campanhas educativas, reforçando ou combatendo preconceitos. 0 PCN chama atenção para o fato de que, queira ou não, a sexualidade está presente nas escolas, seja nos dizeres e desenhos das portas dos banheiros, na convivência entre os alunos, nas aulas de ciências sobre a reprodução humana. Porém "Essa abordagem normalmente não abarca as ansiedades $\mathrm{e}$ curiosidades das crianças, nem o interesse dos adolescentes, pois enfoca apenas o corpo biológico e não inclui a dimensão da sexualidade" (PCN, 1998, p. 292).

Visando reconhecer a importância de um trabalho sistemático de Orientação Sexual dentro das escolas, o PCN defende que a sexualidade engloba as diversas dimensões do ser humano ligada à vida, à saúde, ao prazer e ao bem-estar, e se a escola deseja ter uma visão integrada das experiências vividas pelos alunos, não deve ignorar o tema.

Para a prevenção do abuso sexual com crianças e jovens, trata-se de favorecer a apropriação do corpo, promovendo a consciência de que seu corpo lhes pertence e só deve ser tocado por outro com seu consentimento ou por razões de saúde e higiene. Isso contribui 
para o fortalecimento da autoestima, com a conseqüente inibição do submetimento ao outro (PCN, 1998, p. 293).

A BNCC é apresentada como resultado de um amplo processo de debate, consultas públicas e negociação com diferentes atores do campo educacional e com a sociedade brasileira, e teve uma primeira versão publicada em 2015, que foi submetida a pareceres analíticos de especialistas, associações científicas, análises individuais, de organizações e de redes de educação de todo o país, resultando em uma segunda versão publicada em 2016, que também passou por revisões. Uma terceira versão da base foi disponibilizada em 2017.

A retirada da expressão "orientação sexual" da BNCC não significa exatamente o total silenciamento do debate das questões de gênero nas escolas. o documento cita, como uma competência geral da BNCC,

Exercitar a empatia, o diálogo, a resolução de conflitos e a cooperação, fazendo-se respeitar e promovendo o respeito ao outro, com acolhimento e valorização da diversidade de indivíduos e de grupos sociais, seus saberes, identidades, culturas e potencialidades, sem preconceitos de origem, etnia, gênero, idade, habilidade/ necessidade, convicção religiosa ou de qualquer outra natureza, reconhecendo-se como parte de uma coletividade com a qual deve se comprometer (BNCC, 2017, p. 19).

Além desta diretriz geral, o documento faz algumas menções ao debate sobre questões de gênero e sexualidade, mas realmente está longe de apresentar um avanço e/ou atualização das reflexões se comparado ao PCN de Temas Transversais e Orientação Sexual. Nos conteúdos de Artes, Educação Física, Ciências, Geografia, História, as questões de gênero aparecem quando se fala das habilidades a serem desenvolvidas em cada série. Como exemplo no Ensino de Artes, dança e teatro, fala-se da habilidade de "Discutir as experiências corporais pessoais e coletivas desenvolvidas em aula, de modo a problematizar questões de gênero e corpo" (BNCC, 2017, p. 159) e "Experimentar as possibilidades criativas do corpo e da voz, discutindo questões de gênero e corpo" (BNCC, 2017, p. 161). Sobre o ensino de Educação Física o documento ressalta, entre outras, a habilidade de "Problematizar preconceitos e 
estereótipos de gênero, sociais e étnico-raciais relacionados ao universo das lutas e demais práticas corporais e estabelecer acordos objetivando a construção de interações referenciadas na solidariedade, na justiça, na equidade e no respeito" (BNCC, 2017,p.193). No ensino deCiências está expresso que os alunos devem aprender a"Selecionar argumentos que evidenciem as múltiplas dimensões da sexualidade humana (biológica, sociocultural, afetiva e ética) e a necessidade de respeitar, valorizar e acolher a diversidade de indivíduos, sem preconceitos baseados nas diferenças de gênero (BNCC, 2017, p. 301). A questão de gênero aparece como assunto de interesse também da Geografia quando o documento cita que a "aprendizagem da Geografia favorece o reconhecimento da diversidade e das diferenças dos grupos sociais, com base em princípios éticos (respeito à diversidade sem preconceitos étnicos, de gênero ou de qualquer outro tipo)" (BNCC, 2017, p. 313), pois para analisar as características da sociedade brasileira é necessário "Analisar a distribuição territorial da população brasileira, considerando a diversidade étnico-cultural (indígena, africana, europeia e asiática), assim como aspectos de renda, gênero e idade nas regiões brasileiras" (BNCC, 2017, p. 339). Questões de gênero e protagonismos femininos também aparecem nas descrições dos conteúdos e habilidades do ensino de História, como na passagem que sugere que devese "Identificar as transformações oco no Brasil durante o século $\mathrm{XX}$ e compreender o significado das mudanças de abordagem em relação ao tema" (BNCC, 2017, p. 379).

Apesar dos temas sexualidade e gênero ainda estarem presentes nas proposições da BNCC, não houve um avanço no debate se comparado ao PCN do final da década de 1990. O termo "orientação sexual" presente na primeira versão de 2015 foi suprimido, substituído em alguns trechos pela palavra gênero, atendendo assim, a demanda de setores conservadores do Congresso Nacional. 0 tema surge de forma superficial, sem fazer menção a questão da violência contra a mulher e da persistente desigualdade em relação aos 
homens, homofobia, identidade de gênero, prostituição infantil, pedofilia e outros temas do universo da sexualidade que ganharam destaque nos últimos anos e que poderiam ter sido melhor definidos e incorporados.

Em relação à questão da pluralidade cultural e do ensino de relações étnico-raciais, pelo menos em tese, o tema está ainda mais contemplado, pois entre as propostas da nova BNCC destaca-se a redução de tópicos como História Antiga, Medieval e Moderna para priorizar a História do Brasil, das Américas e da África. A questão da diversidade étnicocultural e da necessidade de promoção do respeito e superação dos preconceitos historicamente arraigados aparece em diversas partes do documento, como habilidades a serem desenvolvidas em diversas áreas.

Porém como já citamos, não são raras as pesquisas que apontam para os desafios da promoção de um ensino realmente atendo a questão da pluralidade cultural e sua importância na formação do povo, da cultura e do território brasileiro. Seja devido ao preconceito historicamente arraigado, que vem associado ao fundamentalismo e intolerância religiosa, seja por falta de oferta ou acesso a especialização e cursos de formação, ausência de materiais didáticos, entre outros. Percebemos que ainda há muito que avançar no sentido de uma educação que promova um debate inter e multicultural. As leis n. 10.639 de 2003 e n. 11.645 de 2008, que fizeram acréscimos a LDB e tornaram obrigatório o ensino de "História e Cultura AfroBrasileira e Indígena" sem duvidas causaram impactos nas escolas, mesmo que muitas vezes de forma ainda tímida, restrita a iniciativas individuais de alguns professores e a comemorações pontuais em alusão ao "Dia do Índio" ou "Dia da Consciência Negra".

Mesmo que consideremos tímidos os avanços, na legislação e na prática cotidiana, em relação ao debate da diversidade e do ensino intercultural, notamos que já foram suficientes para causar uma força contrária, reacionária e conservadora. Falar da história e cultura afro-brasileira sem falar a dimensão da espiritualidade e suas manifestações religiosas é algo extremamente difícil, pois foi 
através das diversas organizações sociais de cunho religioso recriadas no Brasil pelos africanos escravizados, que se preservou grande parte da memória, dos conhecimentos e das línguas destes povos. A intolerância religiosa tem sido um dos principais desafios na implantação de um debate respeitoso sobre a diversidade cultural brasileira e os possíveis diálogos interculturais no ensino.

Não é difícil achar notícias sobre a dificuldade de realização de praticas de ensino dentro da perspectiva das leis n. 10.639/03 e n. 11.645/08, como o caso da escola Centro de Educação Trindade, em Ananindeua, município do estado do Pará, onde os alunos foram proibidos pela direção de apresentar um trabalho sobre uma entidade da cosmologia afro-brasileira. ${ }^{3}$ Podemos citar também o caso da escola Escola Estadual Senador João Bosco de Ramos Lima, de Manaus (AM), onde em 2012, catorze alunos evangélicos do $2^{\circ}$ e $3^{\text {o }}$ ano do ensino médio se recusaram a apresentar na feira cultural um trabalho sobre cultura africana que abordasse aspectos da

3 Ver https://goo.gl/lHoc4S e https://goo. gl/u0ubMX religião tradicional destes povos. Os alunos queriam apresentar um trabalho sobre "Missões Evangélicas na África”, porém o coordenador do projeto entendeu que o tema proposto pelos alunos fugiu a proposta do projeto, que era sobre a diversidade cultural da sociedade brasileira, e o caso foi acompanhado por representantes dos Direitos Humanos, Movimento Religioso de Matriz Africana, Comissão de Diversidade Sexual da Ordem dos Advogados do Brasil $-\mathrm{OAB}^{4}$

\section{Escola Sem Partido e o retrocesso a caminho}

0 Projeto de Lei (PL) "Programa Escola Sem Partido", de autoria do senador Magno Malta (PP) do Espírito Santo, nasceu do movimento "Escola Sem Partido” idealizado em 2003, por iniciativa do procurador do estado de São Paulo, Miguel Nagib, e da influência da bancada conservadora cristã no Congresso Nacional. É um movimento de natureza reacionária que tem tentado barrar a aplicação de um ensino multicultural e de formação crítica nas escolas. Com uma forma peculiar de compreender o

4 Ver https://goo.gl/4Ezu2s e https://goo. gl/RGsi3 
mundo, tal movimento, embasado em mitologias próprias, vem crescendo paulatinamente e ameaçando os atuais avanços em direção a educação para o respeito à pluralidade cultural. Tem como objetivo, basicamente, conter uma suposta influência arbitrária do professor e assegurar a "liberdade" de pensamento e aprendizagem dos alunos segundo a convicção política, ideológica e religiosa de seus pais ou responsáveis, estabelecendo padrões educacionais e regras para a execução do ensino em todo o território nacional.

A "perfeita sintonia" com a Constituição Federal e com a LDB está evidenciada em artigos do PL que determinam que "Art. 2o. A educação nacional atenderá aos seguintes princípios: Ineutralidade política, ideológica e religiosa do Estado; II - pluralismo de ideias no ambiente acadêmico" (PL n. 867, 2015, p. 2). Todavia, tal sentença encontra algumas contradições se avançamos na interpretação do contexto de produção das diretrizes deste projeto. Que tipo de pluralismo de ideias seria este, se o próprio texto da lei defende, como princípio, que é "VII - direito dos pais a que seus filhos recebam a educação moral que esteja de acordo com suas próprias convicções" (PL n. 867, 2015, p. 2), isto é, determinadas temáticas que os pais julguem que afrontam suas próprias convicções não poderão ser debatidas no ambiente escolar democrático, polifônico, aberto a ver, ouvir e conhecer novas realidades, saber diferenciá-las e respeitá-las.

A lei atenta contra a liberdade do professor de interpretar as diretrizes curriculares e ser o protagonista no processo de mediação doensino-aprendizagem nas escolas quando, no seu Art. $4^{\circ}$, diz que no exercício de suas funções, o professor "V - respeitará o direito dos pais a que seus filhos recebam a educação moral que esteja de acordo com suas próprias convicções" (PL n. 867, 2015, p. 2). Porém é função dos professores, como destaca Freire (1996), muito mais que transmitir conteúdos sobre fatos e conceitos, dar condições para que os alunos tenham autonomia para aprender e saber viver em sociedade, isto é ensinar procedimentos de pesquisa e interpretação do mundo, e desenvolver valores 
humanos, uma moral atenta ao respeito às diferenças de todas as naturezas e as liberdades individuais.

Dessa maneira, o PL "Escola Sem Partido" é uma iniciativa retrógrada e preocupante, pois dá a entender que os professores serão vigiados e se instaurará a incapacidade de fazer da escola um ambiente aberto à pluralidade cultural. Os pais dos alunos, talvez mais que os alunos, poderão manifestar suas intolerâncias e preconceitos diante de outras concepções de mundo, o que levará a mais segregação e intolerância entre as pessoas. A liberdade de aprender sugerida pelo projeto poderá cercear as iniciativas legais que tentam valorizar o caráter multicultural do brasileiro, como a obrigatoriedade no ensino de cultura afro-brasileira e indígena, e o debate sobre sexualidade e gênero. Mesmo as teorias científicas se veem "ameaçadas" de censura ou relativização, como a consagrada Teoria da Evolução das Espécies do cientista Charles Darwin, pois segundo o PL dá a entender, a teoria poderia atentar contra as convicções religiosas dos pais e dos alunos adeptos das concepções criacionistas por exemplo.

Essa forma de compreender o mundo, que valoriza apenas a sua própria convicção, e é intolerante a outras, é um atentado violento a educação e os avanços recémconquistados, e torna distante qualquer movimento em direção a valorização dos etnoconhecimento e de um ensino intercultural. Ao fechar os olhos para temas transversais como pluralidade cultural, orientação sexual, ética, pelo simples fato de ir de encontro às próprias convicções, instaurase um contexto perigoso, nada condizente com os princípios constitucionais que garantem a não discriminação de qualquer natureza. O PL "Programa Escola Sem Partido" é proposto por pessoas que não acompanham os debates acadêmicos e cotidianos na área da educação e que afronta aos avanços e direitos recémadquiridos. Apesar de dizer que garante o "pluralismo de ideias no meio acadêmico" (PL n. 867, 2015, p.1), procura definitivamente cercear um ensino em uma perspectiva multicultural e crítica.

Uma consulta pública feita pelo Portal E-Cidadania do Senado 
Federal está aberta e no dia 06/06/17 estavam contabilizados 192.381 votos favoráveis ao projeto e 203.641 votos contrários. A matéria ainda está em tramitação no Senado.

\section{Diálogos interculturais e fronteira entre mito e ciência nas aulas de Geografia e História}

0 mito é um tipo de história, estilo literário e linguagem de difícil definição. 0 mito caracterizase como um elemento das culturas responsável pela disseminação de seus conhecimentos e valores, seja em forma de lendas, fábulas ou estórias, que integram um pensamento "arcaico", seja como forma de ideologia dominante ou falsidades ideológicas, como no caso dos mitos modernos, como o "mito do desenvolvimento" descrito por Furtado (1974), o "mito do progresso" de Dupas (2006), o mito da superioridade racial e cultural europeia, da família perfeita, entre outros tantos. Para Eliade (1972) não é possível definir o mito sem reduzilo. 0 historiador propõe que o mito é uma história sagrada porque

relata um acontecimento ocorrido no tempo primordial, o tempo fabuloso do "princípio". Em outros termos, o mito narra como, graças às façanhas dos
Entes Sobrenaturais, uma realidade passou a existir, seja uma realidade total, o Cosmo, ou apenas um fragmento: uma ilha, uma espécie de vegetal, um comportamento humano, uma instituição. É sempre, portanto, uma narrativa de uma "criação": ele relata de que modo algo foi produzido e começou a ser. $\mathrm{O}$ mito fala apenas do que realmente ocorreu, do que manifestou plenamente. [...] E mais: é em razão das intervenções dos Entes Sobrenaturais que o homem é o que é hoje, um ser mortal, sexuado e cultural (ELIADE, 1972, p. 22).

Ainda que Eliade considere os mitos pertencentes a um sistema de pensamento arcaico, ele mesmo destaca que os mitos estão presentes na modernidade de forma camuflada e cita que o "retorno às origens", muito importante para as sociedades "arcaicas", sobrevive nas sociedades históricas, sobretudo no que tange o enaltecimento nas sociedades europeias modernas. Segundo definição detalhada do Dicionário Houaiss da Língua Portuguesa podemos notar os múltiplos usos e significados do verbete:

Mito. s. m. 1 relato fantástico de tradição oral, ger. protagonizado por seres que encarnam, sob forma simbólica, as forças da natureza e os aspectos gerais da 
condição humana; lenda; fábula; mitologia (m. é lenda dos índios do Xingu) (os m. da Grécia antiga) (o m. de Narciso) 2 narrativa acerca dos tempos heróicos, que geralmente guarda um fundo de verdade ( o m. dos argonautas e do velocino de ouro) 3 Antropol. relato simbólico, passado de geração em geração dentro de um grupo, que narra e explica a origem de determinado fenômeno, ser vivo, acidente geográfico, instituição, costume social, etc. ( o m. da criação do mundo) 4 p.ext. representação de fatos e/ou personagens históricos, frequentemente deformados, amplificados através do imaginário coletivo e de longas tradições literárias orais ou escritas (o m. em torno de Tiradentes) 5 exposição alegórica de uma ideia qualquer de uma doutrina ou teoria filosófica: fábula, alegoria ( o m. da utopia, de More) (o m. da caverna, de Platão) 6 fig. construção mental de algo idealizado, sem comprovação prática; ideia, estereótipo (o m. do detetive infalível) ( $\mathrm{o} \mathrm{m}$. do bom selvagem) 7 representação idealizada do estado da humanidade, no passado ou no futuro (o paraíso terrestre segundo Nostradamus: $m$. ou profecia?) 8 valor social ou moral questionável, porém decisivo para o comportamento dos gruposhumanosem determinada época (o $\mathrm{m}$. do negro de alma branca) (o m. da virgindade) 9 afirmação fantasiosa, inverídica, que é disseminada com fins de dominação, difamatórios, propagandísticos, como guerra psicológica ou ideológica ( o mito do comunista que come criancinhas) (o m. da inferioridade mental dos negros) 10 afirmação ou narrativa inverídica, inventada, que é sintoma de distúrbio mental; fabulação ( sua ideia de que está sendo perseguida não passa de um m.) Etim latim (mÿthos, i'fábula, história, do grego mùthos ou 'fábula, relato, discurso, palavra; ver mit(i/o); f. hist. 1836 mytho, 1913 mito. sin/ var. ver sinonímia de quimera (HOUAISS, 2001).

0 significado do termo "história" vem do antigo termo

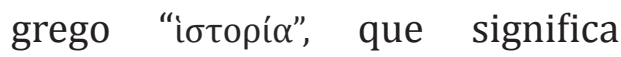
pesquisa, conhecimento através da investigação. Enquanto uma ciência moderna a História é possuidora de métodos específicos que a distancia de outros tipos de narrativas. A História, para afirmar-se como ciência, procurou se fundamentar na descrição dos fatos baseando-se em documentos tomados como a verdade materializada. Porém autores de diferentes filiações teóricas como Hall (2003) e Foucault (1996) fazem a crítica à maneira como a história tem tratado os documentos, como verdadeiros, autênticos e bem informados no que dizem, propondo a problematização do contexto de 
produção dos mesmos e do caráter cientificista do fazer histórico.

A Geografia como um saber ocidental,também tem suasorigens mais antigas remetidas à Grécia. Desenvolveu-se como ciência principalmente na Alemanha e na França do século XIX, e desde então, influenciada por diferentes concepções epistemológicas, busca se constituir como um saber particular, com objetivos e métodos científicos específicos, "a Geografia”. Claval (1999), porém, chama atenção que esta geografia não é tão universal e independente dos valores particulares e étnicos como a concebemos. Para o autor, não podem ignorar a importância que os diferentes povos atribuem ao seu meio ambiente, suas estruturas sociais, organização dos espaços e suas relações com outros mundos. Reconhecendo que é um campo pouco explorado, o autor sugere um percurso metodológico e campos para explorar os estudos etnogeográficos: as representações do mundo, das relações com o meio, da vida social, para poder compreender como os homens constroem a sua ideia de "mundo" e poder caminhar para uma pesquisa voltada a uma geografia histórica.

A historicidade $\mathrm{e}$ geograficidade do pensamento e das interpretações de mundo de povos diversos que podem ser acessadas através de suas mitologias, nos permitem investigar que os diferentes grupos humanos têm suas maneiras de buscar uma ordem e razão de ser para as coisas, seus arranjos espaciais, relações sociais e com o meio dito natural, isto é, fazer suas ciências. A fronteira entre o discurso da ciência e do mito é tênue. Adorno e Horkheimer (1985) destacam semelhanças e rupturas entre $o$ mito e a ciência e sugerem que, na fronteira, está o fato de ambos atribuírem significados as coisas do mundo natural e cultural, de quererem manipular a realidade a partir destes conhecimentos, utilizando-se dos signos, símbolos e significações.

A história e a geografia são instrumentos poderosos de transmissão de conhecimentos de geração para geração, e estão relacionadas a tomada de decisões e posicionamento perante $\mathrm{o}$ mundo, isto é, conhecer a geografia e história para fazer a geografia e 
história. Assim como o historiador, “O papel do geógrafo também se estende à produção do político. 0 cotidiano é um produtor do fenômeno político na medida em que mostra como as diferenças se estabelecem aconselhando a tomada de posições" (SANTOS, 1996, p. 13).

A sociedade em geral está acostumada a uma lógica simplificada entre o significado e o significante, e os sentidos das palavras são tomados como dados em si mesmos, Os mitos estão presentes na modernidade de diversas formas, mas geralmente está associado à ideia de mentira, falsidades, lendas do pensamento primitivo. Interessa-nos chamar atenção para a importância de lermos as palavras para pensar para quais finalidades são usadas. Os objetos de discurso são históricos, não dizem a mesma coisa em tempos diferentes. Como bem nos sugere Foucault (1996), as instituições que exercem poder instrumentalizam as palavras para alcançar fins, e produzir discursos. Banalizar o conceito de mito como mentira serviu e vem servindo para inferiorizar saberes não-europeus e ocultar sua força ordenadora nos nossos tempos, de racionalismos científicos, progressos técnicos, heróis nacionais e promessas inconclusas. A linguagem mítica está presente no ordenamento das sociedades e suas culturas, sejam elas modernas, não-modernas, ou pós-moderna, estejam elas no passado ou no presente. No diálogo com Foucault destacamos a importância de entender que dotamos as palavras de poder, e que é preciso problematizar seus significados, entendendo-as como construção histórica imersa em intencionalidades.

Além dos documentos citados, relativos à legislação nacional, analisamos os Cadernos de Orientação Curricular (COC) da Secretaria de Educação do Estado do Acre (SEE/AC) da área de Geografia e História. O COC da área de Geografia, ainda que minimamente, aponta para valorização do etnoconhecimento e propõe que, para o aluno aprender a "utilizar sistemas de orientações simples para localizarse e deslocar-se nos diferentes espaços onde vive" (ACRE/SEE, 2010, p. 34), é necessário que seja trabalhado, como conteúdo, "o conhecimento de sistemas 
de orientações construídos por outros povos (indígenas brasileiros, incas, astecas, maias e etc)" (ACRE/SEE, 2010, p. 34).

0 documento da área de História descreve que um dos objetivos do ensino é: "Compreender a história como processo a partir da experiência humana e o conhecimento histórico como resultado do ofício do historiador" (ACRE/SEE, 2010, p. 34). Nesse aspecto podemos notar que há uma clara delimitação de que o conhecimento sobre a História é produzido por aqueles que estão autorizados a fazê-lo: os historiadores. 0 conhecimento histórico deriva, necessariamente, da atividade de pesquisa do historiador, o que poderia nos levar ao limite que diferencia história e mito. Porém ao analisarmos as sociedades onde a história é contada e recontada através dos mitos também percebemos que o conhecimento é produzido por pessoas específicas, que se dedicam a esse oficio, pois também lá não é qualquer um que constrói o conhecimento histórico. Os poetas e os xamãs são os portavozes do discurso mítico, aqueles autorizados para o exercício da função enunciativa da verdade, que cantam e contam a história, que alimentam a memória social de uma população. Daí falar nas fronteiras (lugar de contato) e limites (definição das diferenças) entre os mitos e as ciências.

Hissa (2002) nos inspira a usar a metáfora espacial para refletir sobre as relações entre o pensamento científico e o pensamento mítico, e para o geógrafo, esses são conceitos que se interpenetram, mas não se equivalem. Ambos fazem refletir sobre as relações de poder por se tratarem de demarcações que visam definir áreas de influência e controle, os territórios políticos, os campos de saber, etc. "Focalizase o limite: ele parece consistir de uma linha abstrata, fina o suficiente para ser incorporada pela fronteira. A fronteira, por sua vez, parece ser feita de um espaço abstrato, areal, por onde passa o limite" (HISSA, 2002, p. 34).

A ciência moderna, essa instituição que começa a surgir, sobretudo a partir do século XVII, como forma de pensamento, procurou traçar os limites bem definidos que a diferenciasse do mito e das 
abordagens metafísicas, na defesa de que a ciência deve ser objetivista e prática, uma razão técnica cientificamente orientada para o intelectualismo e o utilitarismo antropocêntrico a serviço do capital. Para culturas ditas arcaicas e/ou tradicionais, como as dos diversos povos indígenas no Brasil, o mito é uma realidade, refere-se às coisas que existem, é uma forma que os povos encontraram de entender a complexidade da vida. Para Munduruku (2015) o mito é, para o pensamento indígena, o mesmo que história, uma leitura de mundo, uma narrativa sobre os fatos: são as formas de contar a origem de um povo e seus feitos. Talvez por isso o neologismo proposto por João Ribeiro, em 1919, para designar, a narrativa popular, o conto tradicional, as mitologias como folclore, como "Estória”, diferente de História, não tenha tido grande aceitação: história são Histórias.

\section{Diálogos interculturais no} planejamento das aulas: as diferentes versões sobre a origem do mundo e da humanidade

antos (2007) propõe que é necessário um processo de descolonização do pensamento para a construção de projetos sociais globais mais justos, e a ecologia dos saberes seria uma parteimportante desse movimento epistemológico, contrapondose à "monocultura da ciência moderna", baseando-se na ideia de que os saberes são heterogêneos e propondo interações sustentáveis e dinâmicas entre os diversos tipos de conhecimentos.

As reflexões de Claval (2006) sobre a geografia cultural e as etnogeografias nos apontam caminhos para pensar o ensino de Geografia em uma perspectiva menos etnocêntrica e mais intercultural. Investigar as geografias concebidas e praticadas por diversos grupos, seus esforços cartográficos, é propor um enfoque por muito tempo silenciado na história do pensamento geográfico: "os significados que as diversas sociedades conferem à sua inserção no espaço, as suas etnogeografias" (CLAVAL, 2006, p. 21).

Para exemplificar nossa proposta de abordagem intercultural no ensino de Geografia e História, em uma perspectiva atenta as diretrizes 
curriculares e a necessidade de um debate nas escolas sobre a pluralidade cultural e combate às intolerâncias étnico-religiosas, escolhemos o tema "A origem do mundo e da humanidade", cujo interesse é compartilhado pelas duas áreas do conhecimento. Buscamos trazer três perspectivas sobre o assunto para que, como ideias e saberes, sejam postas em diálogos, para uma compreensão mais diversificada sobre o tema. 0 enfoque nestas três perspectivas não exclui a existência de muitas outras. Aparentemente distintas, a interpretação dessas narrativas permite-nos um paralelo e conversação entre elas como forma de buscar entender os limites e as fronteiras entre os mitos e as ciências, entendendo que existem diferentes formas de produzir os conhecimentos históricos e geográficos sobre o mundo, a ciência dos historiadores e geógrafos, e as mitologias dos diversos povos e seus saberes.

Escolhemos trazer uma mitologia de amplo conhecimento por parte dos alunos, a narrativa do livro de Gêneses da tradição judaico-cristã, que conta o percurso de Deus durante os sete dias da criação; duas narrativas da África iorubá que explicam como o Céu e a Terra se separaram e como a lama serviu para a modelagem dos seres humanos; e uma apresentação das teorias científicas mais aceitas sobre as origens do mundo e da humanidade: a teoria do Big-Bang e a da Evolução das Espécies.

$\mathrm{Na}$ perspectiva da narrativa do livro de Gêneses, o criador do Universo é um ser onipotente, onipresente, assexuado e sem iguais. E no início “(...) a Terra era sem forma e vazia, e as trevas cobriam o abismo (...)" até que esse “Deus disse: 'Haja luz', e houve luz (...) Deus chamou a luz de dia e as trevas ele chamou de noite" (GÊNESES, 1;3 apud CRUMB, p. 12). Dessa forma, a Terra nasceu e, consequentemente, o mundo. A criação não parou por aí, a terra como porção continental, precisava ser criada. "E Deus disse: 'que a água sob os céus se ajunte em um só lugar, para que a parte seca apareça'” (GÊNESES, 1:9 apud CRUMB, p.12). E assim foi feito sucessivamente, cada coisa no mundo foi criada ao longo de seis dias, pois, segundo essa narrativa, no sétimo Deus descansou. No 
sexto dia "criou o homem à sua própria imagem; (...) E Ele criou macho e fêmea" (GÊNESES, 1:27, apud CRUMB, p. 14).

Os iorubas, povos que constituíram impérios précoloniais na África Ocidental, especialmente, na região do Golfo de Guiné, e que transportaram e preservaram grande parte de seu patrimônio imaterial no Brasil, explicam essa criação de outra forma. Eles possuem uma rica mitologia compilada por Prandi (2001) e destacamos duas narrativas que poderiam ser utilizadas como recurso didático. Segundo Prandi (2001), os iorubas contavam que Oduduá brigou com Obatalá e o Céu e a Terra se separaram. De acordo com a narrativa, antes da existência do mundo, como a gente conhece, tudo estava unido na cabaça primordial, morada dos dois deuses criadores Obatalá e Oduduá. Contudo, surgiu um conflito entre eles por conta da posse dos sete anéis que possuíam. Durante a intensa briga, a cabaça se partiu e a parte inferior, com Oduduá, a Terra, permaneceu embaixo, enquanto a parte superior, com Obatalá, o Céu, permaneceu em cima, separando- se assim para sempre.

Qualquer analogia com a teoria do Big Bang seria forçar a barra? Vejamos: A narrativa científica mais aceita para explicar a criação do Universo é a famosa teoria do Big-Bang, proposta por George Gamow (1904-1968) e Georges Lemaître (1894-1966). Baseia-se em análises químicofísicas sobre o comportamento dos corpos celestes nas galáxias e nos cálculos sobre a expansão do Universo. Dizem que o mundo surgiu após uma gigantesca explosão de um ovo pré-atômico, que concentrava toda a massa cósmica existente até então. Há 10 ou 20 bilhões de anos, a energia teria ficado muito intensa provocando a explosão primordial criadora de tudo (SOARES, 1990). Houve uma grande liberação de energia (Haja luz! Deus disse, e fizeram-se as estrelas). A cabaça (ovo pré-atômico) se rompera, céu e terra se diferenciaram, o espaço e o tempo foram criados, assim como todos os corpos celestes.

Conhecer essas diferentes narrativas e colocar diferentes concepções sobre a origem do mundo para dialogar, significa propor uma ruptura com o 
monopólio da verdade científica no âmbito escolar, no sentido de valorizar outras literaturas, tradições e epistemologias. Trata-se de um movimento que busca reconhecer que diferentes contextos produzem diferentes verdades, a partir de diferentes linguagens e métodos, e que os saberes não devem ser hierarquizados ou silenciados por força daincompreensão dealgumas das partes. Pelo contrário, podem dialogar, perceber semelhanças e diferenças entre si, e através do esclarecimento, buscar formas de convivência respeitosa com seus limites e fronteiras.

E sobre os seres humanos? Segundo a teoria científica mais aceita sobre a evolução das espécies, desenvolvida por Charles Darwin, em meados do século XIX, os diversos seres vivos passam por transformações ao longo do tempo, que geralmente ocorrem para que exista uma adaptação das espécies ao espaço/meio onde habitam. Nesse sentido, a espécie humana também teria passado por um longo processo de pelo menos 5 milhões de anos de evolução genética, distinguindose de outros hominídeos, dos grandes macacos e outros mamíferos placentários (Soares, 1990).

No pensamento mitológico, os seres humanos surgem a partir de um evento fundador do qual participam os deuses demiurgos. A narrativa ioruba diz que "Nanã fornece lama para a modelagem dos homens". O orixá Oxalá, encarregado da criação, tentou fazer os seres humanos de ar, pau, pedra, fogo, azeite e até de vinho de palma, mas nada dava certo, pois ao serem modelados com esses materiais, os humanos se desvaneciam ou ficavam muito duros, ou se consumiam.

Foi então que Nanã Burucu veio em seu socorro. Apontou para o fundo do lago com seu ibiri, seu cetro e arma, e de lá retirou uma porção de lama. Nanã deu a porção de lama para Oxalá, o barro do fundo da lagoa onde morava ela, a lama (...) é Nanã. Oxalá criou o homem, o modelou no barro. Com o sopro de Olorum ele caminhou. Com a ajuda dos orixás povoou a Terra. Mas tem um dia que o homem morre e seu corpo tem que retornar à terra, voltar a natureza de Nanã Burucu. Nanã deu a matéria no começo mas quer de volta no final tudo o que é seu" (PRANDI, 2001, p. 196).

Esta narrativa guarda semelhanças com a narrativa 
judaico-cristã, que afirma que no sexto dia "o Senhor Deus formou o homem do pó da terra, e soprou em suas narinas o fôlego da vida; e o homem tornou-se uma criatura viva" (GÊNESES, 2:7, apud CRUMB, p.15), pois, nas duas narrativas, a imagem do sopro é utilizada como símbolo da vida e ambas se referem ao pó da terra, a lama, como matéria prima criação. A narrativa faz lembrar também a passagem bíblica na qual o DeusCriador que diz que "No suor da tua fronte comerás teu pão, até retornar ao solo, de onde tu vieste; porque tu és pó e em pó retornarás" (GÊNESIS 3:19 apud CRUMB, p. 21). Em ambas as histórias, os demiurgos pedem de volta no final da vida, a matéria prima usada na criação, mas, também guardam significativas diferenças entre si. Nanã, que na cosmologia tem seu arquétipo associado ao feminino e aos mistérios da vida e da morte, compartilha com o princípio masculino, presente na figura de Obatalá, do ato da criação dos humanos. Aqui reside uma significativa diferença com a narrativa judaico-cristã, na qual Deus, apesar de assexuado, é identificado mais ao princípio masculino que ao feminino.

Fazer uma reflexão e propor o diálogo entre diferentes narrativas é um caminho para que os alunos compreendam que existem diferentes epistemologias, tradições religiosas e concepções de mundo que explicam a criação e a existência das coisas a partir da ação de diferentes forças e energias demiurgas. Aos fundamentalistas o recado: a narrativa bíblica, por mais que seja amplamente difundida e aceita, não pode ser considerada uma única verdade e muito menos como uma teoria. É um mito como tantos outros e conhecer outras mitologias como as afro-brasileiras e indígenas, percebendo a analogia entre elas, como no caso da criação dos humanos a partir do sopro divino e da lama da terra, pode contribuir para que os alunos tenham uma visão menos fundamentalista de suas práticas religiosas eaprendam a respeitar outras tradições, contribuindo para a compreensão e respeito à pluralidade cultural que caracteriza o povo brasileiro.

\section{Considerações finais}

A Geografia e a História se consolidam, assim como as outras ciências humanas, no contexto de 
transformações sociais, políticas e econômicas que caracterizam o século XIX, o século do imperialismo, da industrialização e do avanço do racionalismo ancorado em ideologias racistas e etnocêntricas. Portanto, a Geografia e a História oficiais, assim como todas as ciências, são partes de um conjunto de conhecimentos étnico-culturais históricos e geograficamente construídos (eurocêntricos) que, ao apresentar-se como ciência moderna, torna-se um saber hegemônico, verdade última e forma "mais evoluída" de produção do conhecimento.

Com o intuito de construir uma proposta de ensino intercultural, propomos o planejamento de aulas de Geografia e História utilizando como recurso didático narrativas de tradição oral e escrita sobre a origem do mundo e da humanidade com objetivo de perceber as diferentes possibilidades de se fazer geografia e história, levantando o debate sobre os limites e fronteiras entre as mitologias e as ciências. Os mistérios acerca desses fenômenos encontram diferentes explicações para diversos povos e não devem ser atribuídos valores hierarquizantes ou estigmatizantes e sim, incentivado um diálogo harmonioso, a coexistência de diferentes formas de pensamento, a ecologia de saberes. 0 universo das histórias pode ser um caminho para problematizar a visão folclorizada que reduz a mitologia e a literatura de tradição oral a um pensamento primitivo, de interesse restrito na educação de crianças.

Acreditamos que os avanços na legislação que rege as práticas educativas e os currículos só produzirão os efeitos desejados se houver um amplo processo de formação de professores, produção de materiais didáticos e vontade política de toda a comunidade escolar. Somente assim podem ser promovidas atividades que despertem a valorização da cultura nacional e que revejam paradigmas etnocêntricos, que teimam em reproduzir preconceitos sobre as culturas e práticas sociais indígenas, afro-brasileiras e de outros setores marginalizados.

Salientamos ainda que o PL "Escola Sem Partido" e outras ações pontuais de grupos religiosos

fundamentalistas 
politicamente organizados tem agido no interesse de promover a censura dentro das escolas, e isso não pode ser visto como algo normal, pois parte de um princípio falacioso que prega a neutralidade científica. As escolas precisam continuar laicas, abertas aos debates de concepções políticas, ideológicas e culturais diversas. É preciso perceber que não há neutralidade no ato educativo e em nenhuma ação humana e que o pluralismo de ideias previsto no ato educativo visa desenvolver o espírito de respeito entre os desiguais e a igualdade de direitos.

\section{Referências}

ACRE, Secretaria de Estado da Educação. Série Orientações Curriculares para o Ensino Fundamental CADERNO 1 Geografia. Rio Branco, 2010.

ACRE, Secretaria de Estado da Educação. Série Orientações Curriculares para o Ensino Fundamental CADERNO 1 História. Rio Branco, 2010.

ADORNO, T. W., HORKHEIMER, M. Dialética do esclarecimento: fragmentos filosóficos. Rio de Janeiro: J. Zahar Editor, 1985.

BRASIL. Constituição da República Federativa do Brasil. Disponível Em: http://www.planalto.gov.br/ ccivil_03/Constituicao/Constituicao. htm Acesso em 09 de setembro de 2016.
BRASIL. Lei de Diretrizes e Bases da Educação Nacional. Disponível Em: http://www.planalto.gov.br/ ccivil_03/leis/L9394.htm Acesso em 09 de setembro de 2016.

BRASIL. Secretaria de Educação Fundamental. Parâmetros curriculares nacionais: terceiro e quarto ciclos: Apresentação dos temas transversais. Brasília: MEC/ SEF, 1998.

BRASIL. Secretaria de Educação Fundamental. Parâmetros curriculares nacionais: Volume 10.2 - Temas Transversais - Pluralidade Cultural. Brasília: MEC/SEF, 1998.

BRASIL. Secretaria de Educação Fundamental. Parâmetros curriculares nacionais: Volume 10.2 - Temas Transversais - Orientação Sexual. Brasília: MEC/SEF, 1998.

BRASIL. Ministério da Educação. Diretrizes Curriculares Nacionais Gerais da Educação

Básica. Brasília: MEC, SEB, DICEI, 2013.

BRASIL. Coordenação de Comissões Permanentes - Projeto de Lei n. 867, de 2015. Inclui, entre as diretrizes e bases da educação nacional, o "Programa Escola Sem Partido".

Catraca Livre. Escola proíbe aluno de apresentar trabalho sobre candomblé. Geledés. Disponível em: https://goo. gl/u0ubMX. Acesso: 05/04/2017. CLAVAL, P. História da Geografia. Edições 70: Lisboa/ Portugal, 2006. CLAVAL, P. Etnogeografias conclusão. Revista Espaço e Cultura, UERJ, RJ, n.7, JAN/JUN DE 1999. CRUZ , C. S.; JESUS, S. S. Lei n. 11.645/08: A escola, as relações 
étnicas e culturais e o ensino de história - algumas reflexões sobre essa temática no PIBID. Trabalho XXVII Simpósio Nacional História, Natal, RN, 22-26 julho, 2013.

CRUMB, R.. Gênesis. Tradução Rogério de Campos. São Paulo: Conrad Editora do Brasil, 2009.

DAMÁZIO, E. S. P. Multiculturalismo versus interculturalismo: por uma proposta intercultural do Direito. Revista Desenvolvimento em Questão. Editora UNIIJUÍ: Ijuí, RS, Ano 6, n. 12, jul./dez. 2008.

DUPAS, G. 0 mito do progresso; ou progresso como ideologia. São Paulo: Editora UNESP, 2006.

ELIADE, M. Mito e realidade. São Paulo: Perspectiva, 1972.

FOUCAULT, M. A Ordem do discurso. Aula inaugural no College de France pronunciada em 2 dezembro 1970. São Paulo: Loyola, 1996.

FREIRE, P. Pedagogia da autonomia: saberes necessários para a prática educativa. Rio de Janeiro, EGA, 1996.

FURTADO, C. 0 mito do desenvolvimento econômico. 4.ed., Rio de Janeiro, Paz e Terra, 1974.

GATINHO, A. A. As dificuldades da implementação da educação das relações étnico-raciais no Município de Rio Branco- AC XVI ENDIPE - Encontro Nacional de Didática e Práticas de Ensino UNICAMP - Campinas - 2012.

HALL, S. Da Diáspora: identidades e mediações culturais. Tradução de Adelaine La Guardia Resende e outros. Belo Horizonte: Editora UFMG, Brasília: Representação da UNESCO no Brasil, 2003.
HISSA, C. E. V. A mobilidade das fronteiras: inserções da geografia na crise da modernidade. Belo Horizonte: UFMG, 2002.

HOUAISS, A. Dicionário Houaiss da Língua Portuguesa. Editora Objetiva, 2001, 1a Edição.

LOPES, P. Alunos evangélicos se recusam a fazer trabalho de cultura africana. Blog do Tarso. Disponível em: https://goo.gl/4Ezu2s. Acesso: 05/04/2017.

MELO, T. Evangélicos se recusam a apresentar projeto sobre cultura africana, no AM. Portal G1 AM. Disponível em: https://goo.gl/RGsi3. Acesso: 05/04/2017.

MUNDURUKU, D. Mitos indígenas para crianças, 2015. Disponível em http://goo.gl/y . Acesso em 09 de setembro de 2016.

PRANDI, R. Mitologia dos Orixás. Companhia das letras: SP, 2000.

REIS, I. Diretora proíbe tema de religião de alunos. Diário On Line/ PA. Disponível em: https://goo.gl/ lHoc4S. Acesso: 05/04/2017.

SANTANA, J. V. J. Tensões e desafios para a implantação da lei 10.639/03 no município de Itapetinga - BA. Revista África e Africanidades - Ano 2 - n. 8, fev. 2010. SANTOS, B. S. Dilemas do nosso tempo: globalização, multiculturalismo e conhecimento (entrevista com Boaventura de Sousa Santos). Currículo sem Fronteiras, v. 3, n. 2, p. 5-23, jul./dez. 2003.

SANTOS, B. S. Para além do pensamento abissal: Das linhas globais a uma ecologia de saberes. 
Revista Novos Estudos, n. 79, Novembro 2007.

SANTOS, M. A. Por uma Geografia cidadã: por uma epistemologia da existência. Boletim Gaúcho de Geografia, 21: 7-14, ago., 1996.

SOARES, J. L. 0 Rastro da vida: uma pequena história de bilhões de anos. São Paulo: Moderna, 1990. 